\title{
The activity of antiparkinsonian drug hemantane in models of peripheral inflammation and lipopolysaccharide-induced neuroinflammation
}

\author{
Elena Ivanova*, Inga Kapitsa, Elena Valdman, Tatyana Voronina \\ Laboratory of Psychopharmacology, Zakusov Institute of Pharmacology, Moscow, Russia; \\ *Corresponding Author: iwanowaea@yandex.ru
}

Received 26 November 2012; revised 3 January 2013; accepted 15 January 2013

\section{ABSTRACT}

A large body of literature supports the idea that inflammation exacerbates neurodegenerative pathology. This idea is also supported by the fact that intracerebral or intraperitoneal injection of lipopolysaccharide (LPS) induces symptoms of Parkinson's disease in rats. The aim of this study is to evaluate the anti-inflammatory effects of the novel antiparkinsonian drug hemantane (N-2(adamantyl)hexamethylenimine hydrochloride), which is currently undergoing clinical trials, in models of peripheral inflammation and neuroinflammation and to investigate its ulcerogenic action, which is a common side effect of nonselective nonsteroidal anti-inflammatory drugs. Acetic acid-induced peritonitis in mice was used as a model of peripheral inflammation. Effect on the stomach was investigated in rats were deprived of food for 16 hours and then were treated with $0.2 L_{50}$ of hemantane or the comparator drug diclofenac sodium per os. Injection of LPS in the left substantia nigra pars compacta in rats was chosen as a model of neuroinflammation. LPS-induced body weight loss, forelimb akinesia and behavioral changes caused by irritating odor were registered in rats. Hemantane in the dosage range of $10-40 \mathrm{mg} / \mathrm{kg}$ demonstrates anti-inflammatory activity and significantly decreases the intensity of exudative reaction in a model of acetic acid-induced peritonitis in mice. Additionally, at the dose of 0.2 $\mathrm{LD}_{50}$ orally it did not damage the gastric mucosa of rats. In a model of neuroinflammation induced by a unilateral injection of LPS, hemantane (10 $\mathrm{mg} / \mathrm{kg}$ ) prevents weight loss, development of forepaw akinesia contralateral to the operation, and smell disturbance in rats. Effectiveness of hemantane in the animal models of peripheral inflammation and neuroinflammation make it possible to suggest a new application of hemantane as a safe anti-inflammatory drug.

Keywords: Parkinson's disease; Hemantane; Peripheral Inflammation; Ulcerogenic Effect; Neuroinflammation; Lipopolysaccharide

\section{INTRODUCTION}

Neuroinflammation is a factor which raises the risk of developing this pathology and exacerbates neurodegenerative diseases [1-2]. Microglial activation has been observed in the substantia nigra (SN) and striatum of patients with Parkinson's disease (PD) [3]. Elevated levels of proinflammatory cytokines such as tumour necrosis factor- $\alpha$, interleukin (IL)- $1 \beta$ and IL- 6 have been demonstrated in the cerebrospinal fluid and striatum in PD brains [4-7]. Upregulation of inducible nitric oxide synthase and cyclooxygenase-2 (COX-2) containing amoeboid microglia has been observed in the SN of PD patients [8].

Importance of the inflammatory component in PD etiology and pathogenesis is confirmed by results of epidemiological studies demonstrating that nonsteroidal antiinflammatory drugs (NSAIDs) decrease the risk of developing PD $[9,10]$. Gram-negative bacterial endotoxin lipopolysaccharide (LPS) was demonstrated to be a potent microglial cell activator that induces death of dopaminergic neurons both under the conditions of acute as well as chronic intracerebral administration and in case of acute systemic administration in animals [11-13].

Glutamate excitotoxicity plays an important role in PD pathogenesis. It is known that the chronic overactivation of glutamatergic receptors by N-methyl-D-aspartate (NMDA) results in increased levels of neuroinflammatory markers in the frontal cortex in rats [14].

The above evidence indicates that the search for antiparkinsonian drugs with anti-inflammatory properties is of considerable importance; as such, investigation of 
NMDA antagonists, including derivatives of adamantane, is well advised.

A new antiparkinsonian drug hemantane (N-2(adamantyl)hexamethylenimine hydrochloride) was developed by FSBI "Zakusov Institute of Pharmacology" RAMS", Moscow. Hemantane is effective in animal models and in patients with early stages of PD. It has a complex mechanism of action that involves uncompetitive, low-affinity NMDA receptor open-channel blocking. Additionally, hemantane exhibits antiradical and immunotropic effects [15].

The aim of this study is to evaluate the anti-inflammatory effects of the antiparkinsonian drug hemantane in models of peripheral inflammation in mice and LPSinduced neuroinflammation in rat SN and to investigate its ulcerogenic action, which is a common side effect for nonselective NSAIDs. To objectively assess the influence of hemantane on peripheral inflammation, we employed one of the extensively used and highly effective NSAIDs diclofenac sodium as a comparator drug [16-19]. But along with high effectiveness, diclofenac sodium has some side effects owing to nonselective inhibition of COX-2, with ulcerogenic effect being the most common [20-22]. For this reason diclofenac sodium was also used to evaluate the influence of hemantane on the stomach mucosa of rats.

\section{METHODS}

Male white outbred rats weighing 380 to $420 \mathrm{~g}$, male white outbred rats weighing 210 to $240 \mathrm{~g}$ and male white outbred mice weighing 27 to $30 \mathrm{~g}$ were housed in standard conditions: constant temperature $\left(22^{\circ} \mathrm{C} \pm 1{ }^{\circ} \mathrm{C}\right)$, humidity (relative, $30 \%$ ) and a $12 \mathrm{~h} \mathrm{light/dark} \mathrm{cycle.} \mathrm{Use} \mathrm{of}$ the animals and protocol procedures were carried out in accordance with the regulations set forth by the Ethical Committee for the use of Laboratory animals at FSBI "Zakusov Institute of Pharmacology" RAMS, Moscow.

To assess the anti-inflammatory effect of hemantane in the model of peripheral inflammation, a model of peritonitis in mice was used. Peritonitis was induced by intraperitoneal (i.p.) injection of $1 \%$ acetic acid at the dose of $1 \mathrm{ml}$ per $100 \mathrm{~g}$ of animal weight [23]. Mice were divided into 5 groups, from 8 to 15 mice in each. An hour before the administration of phlogogen, animals of the control group were given saline i.p. Mice of the comparator drug group received diclofenac sodium (Hemofarm) i.p. $10 \mathrm{mg} / \mathrm{kg}$. Determination of the diclofenac sodium dose is based on literature [24-26] and our preliminary results. Mice of the other three groups received hemantane i.p. at three doses $10,20,40 \mathrm{mg} / \mathrm{kg}$, at which its antiparkinsonian action was demonstrated in some animal PD models [15,27]. Three hours after injection of the acetic acid the exudate from the abdominal cavity was collected and its amount was measured.
Effect on the stomach was investigated in rats weighing 210 to $240 \mathrm{~g}$ which were deprived of food for 16 hours. Animals were divided into 3 groups. Rats of the first group received $0.2 \mathrm{LD}_{50}$ of hemantane $(114 \mathrm{mg} / \mathrm{kg})$, rats of the second group received $0.2 \mathrm{LD}_{50}$ of diclofenac sodium $(74 \mathrm{mg} / \mathrm{kg})$ and rats of the third control group were given saline via oral gavage. The ulceration intensity of gastric mucosa was evaluated in 3 hours on a scale from 0 to 4: 0 - no lesions; 0.5 -hyperemia; $1-$ individual small lesions ( 1 or 2 point hemorrhages); 2 multiple lesions (erosions, point hemorrhages); 3 -multiple major lesions (erosions, hemorrhages); 4-severe lesions over all the stomach (massive hemorrhages, erosions, perforation) [23].

To assess the influence of hemantane on the neuroinflammation in rats, we used the PD model induced by the intracerebral injection of LPS (Escherichia coli, Serotype 0, SIL2630, Sigma) [28]. Rats weighing 380 to 420 $\mathrm{g}$ were anaesthetized with pentobarbital sodium (45 $\mathrm{mg} / \mathrm{kg}$ ). Then animals were given unilateral stereotaxic injection of LPS (10 $\mu \mathrm{g}$ LPS in $2 \mu 1$ Ringer's solution) or Ringer's solution (passive control group) in the left substantia nigra pars compacta $(\mathrm{SNc})$ at the following coordinates: $\mathrm{AP}-4.0 \mathrm{~mm}, \mathrm{ML}-2.0 \mathrm{~mm}, \mathrm{DV}-8.0 \mathrm{~mm}$, using a $10 \mu 1$ Hamilton syringe [29]. Animals were divided into 3 groups: 1 -Passive control (sham operated animals), 2-Active control (LPS group), 3-LPS + hemantane $(10 \mathrm{mg} / \mathrm{kg} / \mathrm{day})$. For the LPS induced neuroinflammation test we used hemantane at the dose of $10 \mathrm{mg} / \mathrm{kg}$, at which it had an antiparkinsonian effect in a number of animal PD models and produced a therapeutic action in a rat model of levodopa-induced dyskinesia [15,27,30]. Hemantane was administrated i.p. daily starting one day before the operation. Animals of the LPS and sham operated groups received saline i.p. daily starting one day before the operation. Body weight was registered during the experiment.

On day 7 after the stereotaxic operation the "Cylinder test" was performed to estimate forelimb akinesia as a characteristic of unilateral LPS-induced lesion [31-33]. This test assesses the use of the forelimb to support the body against the walls of a cylinder. The rat was placed into a transparent cylinder (diameter $18 \mathrm{~cm}$, height 45 $\mathrm{cm})$. The number of wall contacts performed independently with the left and the right forepaw were counted for 2 min and later scored from the tape up to a total of 20 touches.

In 3 weeks after the operation the influence of hemantane on the rat's olfactory impairment induced by LPS injection was estimated using a modification of the method described by Lemasson and coworkers [34]. The rat was placed on a square arena (measuring $60 \times 60 \mathrm{~cm}$ with the wall height of $30 \mathrm{~cm}$ ) divided into 9 equal squares. A drop of citrus essential oil was brought into 
one of the squares at the corner of the arena. The arena was divided into the three parts depending on the distance to the odor source: part 1: the square marked with essential oil; part 2: three squares at a distance of 20 to $40 \mathrm{~cm}$ from the odor source; part 3: three squares at a distance of 40 to $60 \mathrm{~cm}$ from the odor source. The time spent in each part of the arena and the number of crossings into area 1 were recorded over 2 minutes.

Animals were randomized and a normality test was performed to check whether the assumptions required for standard parametric analysis of variance (ANOVA) were satisfied. The Statistica 8 software was used to perform statistical analyses using Mann-Whitney test and Student's $t$-test. Statistical significance was set at $\mathrm{p}<0.05$. Data in the tables are expressed as mean \pm SEM. Data in the figures are expressed as mean $\pm \mathrm{SD}$.

\section{RESULTS}

In the model of peripheral inflammation, hemantane at the chosen dosage range decreased the mass of peritoneal exudate in mice by $32 \%$ to $48 \%$ compared with the active control $(p<0.05)$. The greatest anti-inflammatory effect was seen with the $20 \mathrm{mg} / \mathrm{kg}$ dose. No significant difference was demonstrated between the effect of hemantane $20 \mathrm{mg} / \mathrm{kg}$ and the anti-inflammatory action of the comparator drug diclofenac sodium $10 \mathrm{mg} / \mathrm{kg}$, which induced 59\% decrease of peritoneal exudate mass (Figure 1).

Hemantane at the dose of $0.2 \mathrm{LD}_{50}$ did not influence the gastric mucosa of rats: no changes in gastric mucosa were seen in the Hemantane group or intact group (Table 1). In contrast to the animals given hemantane, the rats receiving the nonselective $\mathrm{COX}-1 / \mathrm{COX}-2$ inhibitor diclofenac sodium at the dose of $0.2 \mathrm{LD}_{50}$ had multiple gastric mucosa lesions with an average score of 2 .

It was demonstrated that LPS-induced neuroinflammation caused weight loss in rats as early as in the first days after the operation. In animals of the LPS group weight decreased by $12.2 \mathrm{~g}$ relative to baseline (i.e. before the stereotaxic operation) already during the first 3 days after the operation; another $11.9 \mathrm{~g}$ were lost by day 8 (Table 2). LPS-induced weight loss in rats that received hemantane $10 \mathrm{mg} / \mathrm{kg}$ was not as pronounced as in the active control group. Hemantane reduced weight loss by a factor of 1.3 on day 3 and by a factor of 3.5 on day

Table 1. Influence on gastric mucosa in rats.

\begin{tabular}{cc}
\hline Groups & Ulceration score \\
\hline Intact control & $0 \pm 0$ \\
Hemantane, $114 \mathrm{mg} / \mathrm{kg}$ per os & $0 \pm 0$ \\
Diclofenac sodium, $74 \mathrm{mg} / \mathrm{kg}$ per os & $2 \pm 0.3^{*}$ \\
\hline
\end{tabular}

${ }^{*}$ significant vs. Intact control, $\mathrm{p}<0.05$ (Mann-Whitney test).
8 compared with rats of the LPS group. Sham operated rats did not lose weight after the surgical procedure.

In the "Cylinder test", LPS produced a statistically significant difference in the placement of the contralateral and ipsilateral paw on the cylinder's surface in the active control group: right forelimb use dropped by $17.7 \%$ compared with sham operated animals (Figure 2). This fact characterizes LPS-induced lesion of dopaminergic neurons in the left $\mathrm{SNc}$ of rats that received stereotaxic injection of LPS. In the group of animals that were given hemantane only a tendency towards the reduction in forelimb use contralateral to the lesion was observed. Hemantane induced a twofold decrease in the loss of contralateral paw activity vs. the LPS group.

In three weeks after intranigral injection of LPS, influence of hemantane on the rats' sense of smell was estimated. In the group of active control there was a tendency towards an increase in the time spent in areas 1 and 2 and in the number of crossings into area 1, where the irritating odor was the strongest, relative to sham operated animals (Table 3 ). In the hemantane group the time period spent in area 3 of arena, where the intensity of irritating odor was minimal, was significantly longer and the number of crossings into part 1 of the arena was significantly lower than in the active control group.

\section{DISCUSSION}

It was observed that an uncompetitive, low-affinity NMDA receptor open-channel blocker hemantane [15] in

Table 2. Weight loss in rats after the lipopolysaccharide injecttion.

\begin{tabular}{ccc}
\hline \multirow{2}{*}{ Groups } & \multicolumn{2}{c}{ Weight change in rats } \\
\cline { 2 - 3 } & $\begin{array}{c}\text { day 3 after operation } \\
\text { relative to baseline, } \mathrm{g}\end{array}$ & $\begin{array}{c}\text { day } 8 \text { after operation } \\
\text { relative to day 3, g }\end{array}$ \\
\hline $\begin{array}{c}\text { Sham } \\
\text { operated }\end{array}$ & $5.0 \pm 1.1$ & $2.7 \pm 1.9$ \\
$\begin{array}{c}\text { LPS group } \\
\text { LPS + Hemantane, } \\
10 \mathrm{mg} / \mathrm{kg} \text { i.p. }\end{array}$ & $-12.2 \pm 2.1^{*}$ & $-11.9 \pm 3.6^{*}$ \\
\hline * & $-9.6 \pm 3.2^{*}$ & $-3.4 \pm 2.1$ \\
\hline
\end{tabular}

Table 3. The influence of hemantane on rats' olfactory impairment induced by lipopolysaccharide injection.

\begin{tabular}{|c|c|c|c|c|}
\hline \multirow{2}{*}{ Groups } & \multicolumn{3}{|c|}{ Time spent in each part of arena, s } & \multirow{2}{*}{$\begin{array}{l}\text { Number of } \\
\text { crossings } \\
\text { into area } 1\end{array}$} \\
\hline & area 1 & area 2 & area 3 & \\
\hline Sham operated & $23.3 \pm 10.7$ & $10.0 \pm 3.2$ & $71.3 \pm 6.8$ & $1.5 \pm 0.3$ \\
\hline LPS group & $29.3 \pm 6.5$ & $18.3 \pm 6.3$ & $59.8 \pm 4.1$ & $2.3 \pm 0.2$ \\
\hline $\begin{array}{l}\text { LPS + Hemantane, } \\
10 \mathrm{mg} / \mathrm{kg} \text { i.p. }\end{array}$ & $14.6 \pm 11.5$ & $15.4 \pm 7.0$ & $86.8 \pm 9.9^{*}$ & $0.8 \pm 0.4^{*}$ \\
\hline
\end{tabular}




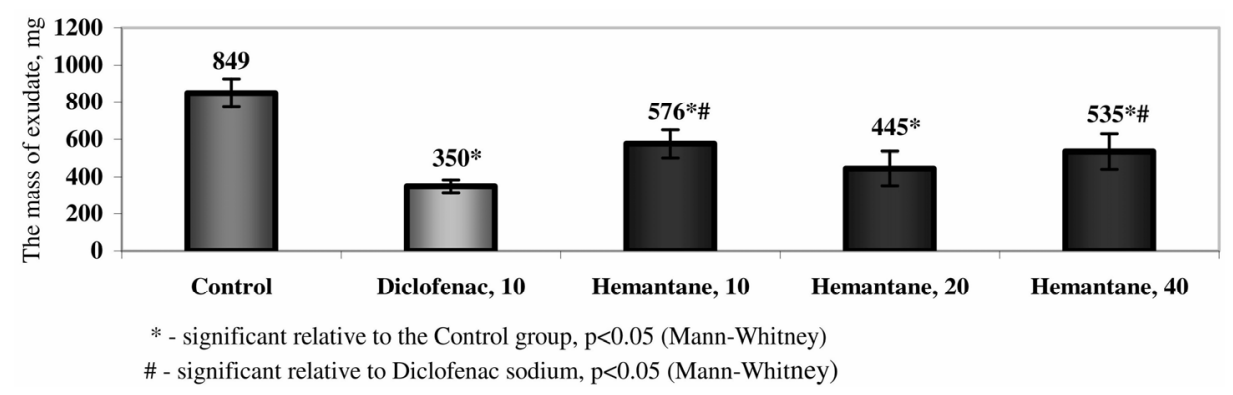

Figure 1. The mass of peritoneal exudate in mice with acetic peritonitis.



Figure 2. Right forelimb use in rats receiving lipopolysaccharide.

the dosage range of 10 to $40 \mathrm{mg} / \mathrm{kg}$ has a strongly pronounced anti-inflammatory activity in the model of acetic peritonitis in mice. These results are in accord with the data concerning the anti-inflammatory activity of NMDA receptor blockers and particularly the effect of dextromethorphan [35]. In addition, it was shown that antagonists of NMDA receptors intensify the therapeutic action of dexamethasone in the rat model of experimental arthritis [36]. Based on the data indicating that neuronal COX-2 expression is regulated by transsynaptic stimulation via NMDA-receptors [37], the modulating activity of hemantane on COX-2 could be hypothesized.

In support of this idea we established that hemantane orally administered at the dose of $0.2 \mathrm{LD}_{50}$ has no ulcerogenic effect in rats, which is common for drugs inhibiting COX-1 [38]. In the experiment described above, a comparator drug - the nonselective COX blocker diclofenac sodium administered orally at the dose $0.2 \mathrm{LD}_{50}$ —had an ulcerogenic side effect.

Induction of neuroinflammation by LPS in cortex, hippocampus, striatum and $\mathrm{SNc}$ is widely used as a model of PD. The bacterial endotoxin rapidly activates microglia whose density is 4 to 5 times higher in dopaminergic brain structures and particularly in $\mathrm{SNc}$; this causes a decrease of dopamine concentration in the striatum and death of dopaminergic neurons $[39,40]$. In the experiment, intranigral LPS injection induced significant weight loss in rats compared to the sham operated animals. This result is confirmed using the data obtained by researches for outbred animals [41]. Hemantane pro- duced a tendency towards a decrease in weight loss on day 3 , and reduced weight loss by a factor of 3.5 on day 8 compared with the active control group.

In the "Cylinder test", the active control group demonstrated akinesia of the right forepaw, which confirmed the degeneration of dopaminergic neurons at the site of LPS injection [32]. The behavior of animals receiving hemantane before and after the stereotaxic surgery did not differ significantly from the behavior of sham operated rats. This indicates that hemantane has a neuroprotective effect by reducing the damage to dopaminergic neurons.

The neurodegenerative process leading to PD begins many years before the onset of the classical motor symptoms. In many cases non-motor symptoms, such as olfactory and memory impairments, sleep abnormalities, anxiety and depression precede the manifestation of motor disturbances and accompany the symptom complex of further stages of PD $[42,43]$. One of the most common sensory problems in patients with PD is the inability to detect and discriminate odors [44-46]. It was shown that the loss of anterior olfactory neurons correlated with disease duration [47]. Sobel et al. [48] determined that PD patients have an impairment in sniffing. In rats with experimental PD, 6-hydroxydopamine lesion induces changes in odor discrimination that are evaluated as hyposmia [49].

In the model of LPS-induced PD, the rats' sense of smell was estimated by testing the behavior changes in the presence of an irritating odor. This method is often 
used to estimate behavior differences caused by odor [50]. In our study hemantane significantly decreased the number of crossings into area 1 of the arena, where the irritating odor was the strongest, and increased the time spent in area 3, where the intensity of irritating odor was minimal, compared with the active control group. It suggests that in rats receiving hemantane the sense of smell was not so damaged as in rats of the LPS group.

Thus, in the PD model induced by an intranigral unilateral LPS injection, which is also considered a model of neuroinflammation, it was shown that hemantane prevents the endotoxin from inducing weight loss, forepaw akinesia contralateral to the operation and behavioral changes caused by irritating odor in rats. This effect of hemantane together with its activity in the model of peripheral inflammation can be interpreted as the ability of hemantane to prevent and retard the process of neuroinflammation.

\section{CONCLUSION}

In summary, our results demonstrate that hemantane in the dosage range of 10 to $40 \mathrm{mg} / \mathrm{kg}$ has an anti-inflammatory effect in the model of peripheral inflammation, namely acetic peritonitis in mice. Moreover, hemantane does not produce the ulcerogenic side effect common to nonselective NSAIDs: at the dose of $0.2 \mathrm{LD}_{50}$ administered orally it did not damage gastric mucosa in rats. Hemantane causes improvements in neuroinflammation manifesting in the correction of behavioral and smell disorders and weight loss that develop after LPS injecttion into the left SNc. The above effects of hemantane make it possible to suggest a new application of hemantane as a safe anti-inflammatory drug.

\section{REFERENCES}

[1] Phani, S., Loike, J.D. and Przeborski, S. (2012) Neurodegeneration and inflammation in Parkinson desease. Parkinsonism \& Related Disorders, 18, S207-S209. doi:10.1016/S1353-8020(11)70064-5

[2] Streit, W.J., Mrak, R.E. and Griffin, W.S.T. (2004) Microglia and neuroinflammation: A pathological perspective. Journal of Neuroinflammation, 1, 14. http://www.jneuroinflammation.com/content/1/1/14 doi:10.1186/1742-2094-1-14

[3] McGeer, P.L., Schwab, C., Parent, A. and Doudet, D. (2003) Presence of reactive microglia in monkey substantia nigra years after 1-methyl-4-phenyl-1,2,3,6-tetrahydropyridine administration. Annals of Neurology, 54, 599-604.doi:10.1002/ana.10728

[4] Nagatsu, T., Mogi, M., Ichinose, H. and Togari, A. (2000) Cytokines in Parkinson's disease. Journal of Neural Transmission. Supplement, 58, 143-151.

[5] Blum-Degen, D., Muller, T., Kuhn, W., Gerlach, M., Przuntek, H. and Riederer, P. (1995) Interleukin-1 beta and interleukin- 6 are elevated in the cerebrospinal fluid of Alzheimer's and de novo Parkinson's disease patients. Neuroscience Letters, 202, 17-20. doi:10.1016/0304-3940(95)12192-7

[6] Mogi, M., Harada, M., Riederer, P., Narabyashi, H., Fujita. J. and Nagatsu, T. (1994) Interleukin-1 beta growth factor and transforming growth factor-alpha are elevated in the brain from Parkinsonian patients. Neuroscience Letters, 180, 147-150. doi:10.1016/0304-3940(94)90508-8

[7] Muller, T., Blum-Degen, D., Przuntek, H. and Kuhn, W. (1998) Interleukin-6 levels in cerebrospinal fluid inversely correlate to severity of Parkinson's disease. Acta Neurologica Scandinavica, 98, 142-144. doi:10.1111/j.1600-0404.1998.tb01736.x

[8] Knott, C., Stern, G. and Wilkin, G.P. (2000) Inflammatory regulators in Parkinson's disease: iNOS, lipocortin-1, and cyclooxygenase-1 and -2. Molecular and Cellular Neuroscience, 16, 724-739. doi:10.1006/mcne.2000.0914

[9] Gao, X., Chen, H., Schwarzchild, M.A. and Ascherio, A. (2011) Use of ibuprofen and risk of Parkinson's disease. Neurology, 76, 863-869. doi:10.1212/WNL.0b013e31820f2d79

[10] Hirsch, E.C. and Hunnot, S. (2009) Neuroinflammation in Parkinson's disease: A target for neuroprotection? The Lancet Neurology, 8, 382-397. doi:10.1016/S1474-4422(09)70062-6

[11] Qin, L., Wu, X., Block, M.L., Liu, Y., Breese, G.R., Hong, J.S., et al. (2007) Systemic LPS causes chronic neuroinflammation and progressive neurodegeneration. Glia, 55, 453-462.doi:10.1002/glia.20467

[12] Kim, W.G., Mohney, R.P., Wilson, B., Jeohn, G.H., Liu, B. and Hong, J.S. (2000) Regional difference in susceptibility to lipopolysacchride-induced neurotoxicity in the rat brain: Role of microglia. The Journal of Neuroscience, 20, 6309-6316.

[13] Lieberman, A.P., Pitha, P.M., Shin, H.S. and Shin, M.L. (1989) Production of tumor necrosis factor and other cytokines by astrocytes stimulated with lipopolysaccharide or a neurotropic virus. Proceedings of the National Academy of Sciences of the United States of America, 86, 6348-6352. doi:10.1073/pnas.86.16.6348

[14] Chang, Y.C., Kim, H.-W., Rapoport, S.I. and Rao, J.S. (2008) Chronic NMDA administration increases neuroinflammatory markers in rat frontal cortex: Cross-talk between excitotoxicity and neuroinflammation. Neurochemical Research, 33, 2318-2323. doi:10.1007/s11064-008-9731-8

[15] Val'dman, E.A. (2001) Application-specific protocol. FSBI Zakusov Institute of Pharmacology, Moscow.

[16] Wober, W. (1999) Comparative efficacy and safety of nimesulide and diclofenac in patients with acute shoulder, and a meta-analysis of controlled studies of nimesulide. Rheumatology (Oxford), 38, 33-38. doi:10.1093/rheumatology/38.suppl 1.33

[17] Caldwell, J.R. (1986) Efficacy and safety of diclofenac sodium in rheumatoid arthritis experience in the United States. The American Journal of Medicine, 80, 43-47.

[18] Akriviadis, E., Hatzigavriel, M., Kapnias, D., Kirimlidis, 
J., Markantas, A. and Garyfallos, A. (1997) Treatment of biliary colic with diclofenac: A randomized, double-blind, placebo-controlled study. Gastroenterology, 113, 225-231. doi:10.1016/S0016-5085(97)70099-4

[19] Jorge, L.L., Feres, C.C. and Teles, V.E. (2011) Topical preparations for pain relief: Efficacy and patient adherence. Journal of Pain Research, 4, 11-24.

[20] Davies, N.M. and Anderson, K.E. (1997) Clinical pharmacokinetics of diclofenac. Therapeutic insights and pitfalls. Clinical Pharmacokinetics, 33, 184-213. doi:10.2165/00003088-199733030-00003

[21] Henry, D., Lim, L.L., Garcia Rodriguez, L.A., Perez Gutthann, S., Carson, J.L., Griffin, M., et al. (1996) Variability in risk of gastrointestinal complications with individual non-steroidal anti-inflammatory drugs: Results of a collaborative meta-analysis. British Medical Journal, 312, 1563-1566. doi:10.1136/bmj.312.7046.1563

[22] Laporte, J., Ibanez, L., Vidal, X., Vendrell, L. and Leone, R. (2004) Upper gastrointestinal bleeding associated with the use of NSAIDs: Newer versus older agents. Drug safety, 27, 411-420. doi:10.2165/00002018-200427060-00005

[23] Shvarts, G.Ya. and Syabaev, R.D. (2005) Methodological instructions on the study of new nonsteroidal anti-inflammatory drugs. In: Chabriev, R.U. Ed., Guidance on experimental (preclinical) study of new pharmacological substances, Meditsina Publishers, Moscow, 695-709.

[24] Bhandage, A., Shevkar, K. and Undale, V. (2009) Evaluation of antinociceptive activity of roots of Glycyrrhiza glabra Linn. Journal of Pharmacy Research, 2, 803-807.

[25] Barkatullah, Ibrar, M., Ali, N., Muhammad, N. and Ehsan, M. (2012) In-vitro pharmacological study and preliminary phytochemical profile of Viola canescens Wall. Ex Roxb. African Journal of Pharmacy and Pharmacology, 6, 1142 -1146. doi:10.5897/AJPP12.061

[26] Purnima, A., Koti, B.C., Thippeswamy, A.H.M., Jaji, M.S., Vishwantha Swamy, A.H.M., Kurhe, Y.V., et al. (2010) Antiinflammatory, analgesic and antipyretic activities of Mimusops elengi Linn. Indian Journal of Pharmaceutical Sciences, 72, 480-485. doi:10.4103/0250-474X.73908

[27] Ivanova, E., Nepoklonov, A., Kokshenev, I., Kapitsa, I., Voronina, T. and Val'dman, E. (2012) Study of anticataleptic activity of hemantane using different routs of drug administration and in combination with levodopa. Biomedicine, 1, 74-81.

[28] Castrano, A., Hererra, A.J., Cano, J., and Machado, A. (1998) Lipopolysaccharide intranigral injection induces inflammatory reaction damage in nigrostriatal dopaminergic system. Journal of Neurochemistry, 70, 1584-1592. doi:10.1046/j.1471-4159.1998.70041584.x

[29] Bures, J., Petran, M. and Zachar, J. (1960) Electrophysiological methods in biological research. Academic Press, New York.

[30] Schallert, T. and Jones, T.A. (1993) "Exuberant" neuronal growth after brain damage in adult rats: The essential role of behavioral experience. Journal of Neural Transplantation \& Plasticity, 4, 193-198.

doi:10.1155/NP.1993.193
[31] Kapitsa, I., Ivanova, E., Nepoklonov, A., Kokshenev, I., Voronina, T. and Val'dman, E. (2011) Comparative study of amantadine and hemantane effects on development of levodopa-induced dyskinesia in rat model of parkinsonian syndrome. Eksperimental'naia I Klinicheskaia Farmakologiia, 7, 9-12.

[32] Schallert, T., Fleming, S.M., Leasure, J.L., Tillerson, J.L. and Bland, S.T. (2000) CNS plasticity and assessment of forelimb sensorimotor outcome in unilateral rat models of stroke, cortical ablation, parkinsonism and spinal cord injury. Neuropharmacology, 39, 777-787. doi:10.1016/S0028-3908(00)00005-8

[33] Kirik, D., Rosenblad, C., Bjorklund, A. and Mandel, R.J. (2000) Long-term rAAV-mediated gene transfer of GDNF in the rat Parkinson's model: Intrastriatal but not intranigral transduction promotes functional regeneration in the lesioned nigrostriatal system. The Journal of Neuroscience, 20, 4686-4700.

[34] Lemasson, M., Delbe, C., Gheusi, G., Vincent, J.D. and Lledo, P.M. (2005) Use of ultrasonic vocalizations to assess olfactory detection in mouse pups treated with 3methylindole. Behavioural Processes, 68, 13-23. doi:10.1016/j.beproc.2004.09.001

[35] Liu, Y., Qin, L., Li, G., Zhang, W., An, L., Liu, B., et al. (2003) Dextromethorplan protects dopaminergic neurons against inflammation-mediated degeneration through inhibition of microglial activation. The Journal of Pharmacology and Experimental Therapeutics, 305, 212-218. doi:10.1124/jpet.102.043166

[36] Lam, F.F.Y. and Ng, E.S.K. (2010) Substance P and glutamate receptor antagonists improve the antiarthritic actions of dexamethasone in rats. British Journal of Pharmacology, 159, 958-969.

doi:10.1111/j.1476-5381.2009.00586.x

[37] Fiebich, B.L., Schleicher, S., Spleiss, O., Czygan, M. and Hüll, M. (2001) Neuroinflammatory circuits in Alzheimer's disease: Interleukin-1 induces cyclooxygenase 2 in human neuroblastoma cells. Proceedings of Meeting of the Volkswagen Foundation and the GEBIN on Psycho Neuro Endocrino Immunology, Regensburg, 15-17 November 2001, 15-16.

[38] Ofman, J.J., MacLean, C.H., Straus, W.L., Morton, S.C., Berger, M.L., Roth, E.A., et al. (2002) A metaanalysis of severe upper gastrointestinal complications of nonsteroidal antiinflammatory drugs. The Journal of Rheumatology, 29, 804-812.

[39] Gao, H.M., Jiang, J., Wilson, B., Zhang, W., Hong, J.S. and Liu, B. (2002) Microglial activation-mediated delayed and progressive degeneration of rat nigral dopaminergic neurons: Relevance to Parkinson's disease. Journal of Neurochemistry, 81, 1285-1297. doi:10.1046/j.1471-4159.2002.00928.x

[40] Iravani, M.M., Leung, C.C., Sedeghian, M., Haddon, C.O., Rose, S. and Jenner, P. (2005) The acute and the long-term effects of nigral lipopolysaccharide administration on dopaminergic dysfunction and glial cell activation. European Journal of Neuroscience, 22, 317-330. doi:10.1111/j.1460-9568.2005.04220.x

[41] Wisse, B.E., Ogimoto, K., Tang, J., Harris, M.K.J., Raines, E.W. and Schwartzm, M.W. (2007) Evidence that 
LPS-induced anorexia depends upon central, rather than peripheral, inflammatory signals. Endocrinology, 148, 5230-5237.doi:10.1210/en.2007-0394

[42] Tolosa, E., Gaig, C., Santamaria, J. and Compta, Y. (2009) Diagnosis and the premotor phase of Parkinson disease. Neurology, 72, S12-S20. doi:10.1212/WNL.0b013e318198db11

[43] Tolosa, E., Compta, Y. and Gaig, C. (2007) The premotor phase of Parkinson's disease. Parkinsonism \& Related Disorders, 13, S2-S7. doi:10.1016/j.parkreldis.2007.06.007

[44] Hawkes, C.H., Shephard, B.C. and Daniel, S.E. (1999) Is Parkinson's disease a primary olfactory disorder? International Journal of Medicine, 56, 33-39.

[45] Tissingh, G., Berendse, H.W., Bergmans, P., DeWaard, R., Drukarch B., Stoof, J.C., et al. (2001) Loss of olfaction in de novo and treated Parkinson's disease: Possible implications for early diagnosis. Movement Disorders, 6, 41-46. doi:10.1002/1531-8257(200101)16:1<41::AID-MDS1017 $>3.0 . \mathrm{CO} ; 2-\mathrm{M}$

[46] Müller, A., Reichmann, H., Livermore, A. and Hummel, T. (2002) Olfactory function in idiopathic Parkinson's disease (IPD): Results from cross-sectional studies in IPD pa- tients and long-term follow-up of de novo IPD patients. Journal of Neural Transmission, 109, 805-811. doi: $10.1007 / \mathrm{s} 007020200067$

[47] Pearce, R.K.B., Hawkes, C.H. and Daniel, S.E. (1995) The anterior olfactory nucleus in Parkinson's disease. Movement Disorders, 10, 283-287. doi: $10.1002 / \mathrm{mds} .870100309$

[48] Sobel, N., Thomason, M.E., Stappen, I., Tanner, C.M., Tetrud, J.W., Bower, J.M., et al. (2011) An impairment in sniffing contributes to the olfactory impairment in Parkinson's disease. Proceedings of the National Academy of Sciences of the United States of America, 98, 4154-4159. doi:10.1073/pnas.071061598

[49] Aguilar, E., Mullol, J., Clementi, V., Perez, V. and Marin C. (2011) Odor discrimination impairment in 6-OHDAlesioned rats: A tool for hyposmia research in Parkinson's disease. Neurodegenerative Diseases, 8.

[50] Furuyashiki, T., Holland, P.C. and Gallagher, M. (2008) Rat orbitofrontal cortex separately encodes response and outcome information during performance of goal-directed behavior. The Journal of Neuroscience, 28, 5127-5138. doi:10.1523/JNEUROSCI.0319-08.2008 